\title{
Transient pain and paresthesias in the hand
}

\author{
Luis S. Beltran • Oren Lerman • Sheel Sharma • \\ Jenny T. Bencardino
}

Published online: 21 June 2013

(C) ISS 2013

\section{Part I}

A 34-year-old man who is a plastic surgeon without any past medical history complained of mild medial elbow pain associated with numbness and tingling along the ulnar aspect of the left hand involving the fourth and fifth fingers, symptoms elicited by elbow flexion. These symptoms had been occurring transiently since the patient could

remember as a child but the symptoms did not interfere with his daily activities throughout his lifetime until the past several months, in which he noticed that after performing a surgical procedure in which his arm was flexed at the elbow for an extended period of time, the symptoms became more prominent on the left hand. MRI of the left elbow was performed (Fig. 1).

Fig. 1 Axial proton density (a) and fat-suppressed T2weighted (b) MR images of the left elbow
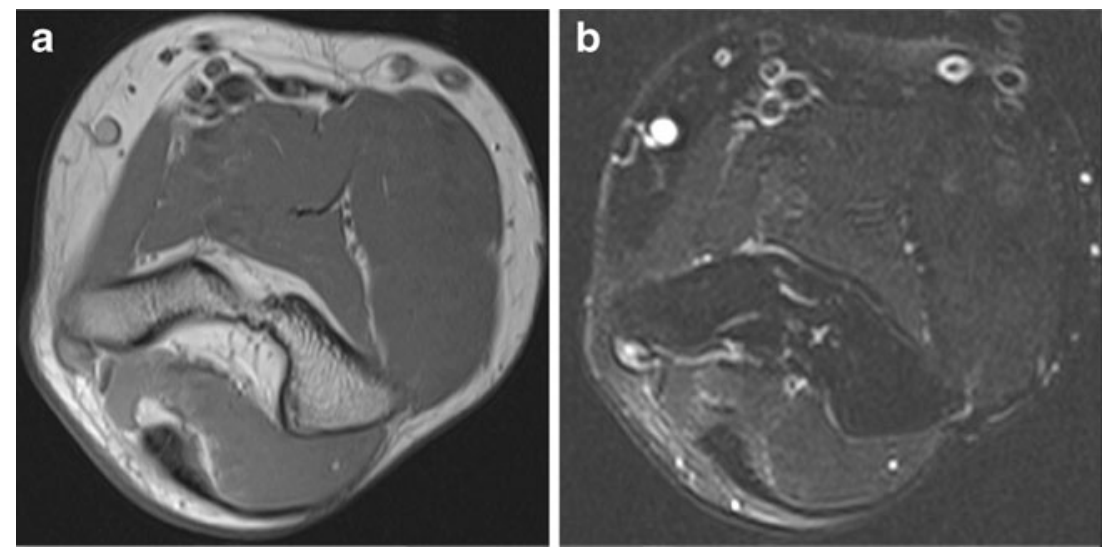

Disclosure The authors declare that they have no conflicts of interest.

The diagnosis can be found at doi: 10.1007/s00256-013-1662-z

L. S. Beltran $(\bowtie)$

Department of Radiology, NYU Hospital for Joint Diseases, 301

East 17th Street, New York, NY 10003, USA

e-mail: luis.beltran@nyumc.org

\section{O. Lerman}

Department of Plastic Surgery, Lenox Hill Hospital,

New York, USA

\section{S. Sharma}

Department of Plastic Surgery, NYU Plastic Surgery Associates,

New York, USA

J. T. Bencardino

NYU Hospital for Joint Diseases, New York, USA 